\title{
Hospital care and repetition following self-harm: multicentre comparison of self-poisoning and self-injury
}

Rachael Lilley, David Owens, Judith Horrocks, Allan House, Rachael Noble, Helen Bergen, Keith Hawton, Deborah Casey, Sue Simkin, Elizabeth Murphy, Jayne Cooper and Navneet Kapur

\section{Background}

Quantitative research about self-harm largely deals with selfpoisoning, despite the high incidence of self-injury.

\section{Aims \\ We compared patterns of hospital care and repetition associated with self-poisoning and self-injury.}

\section{Method}

Demographic and clinical data were collected in a multicentre, prospective cohort study, involving 10498 consecutive episodes of self-harm at six English teaching hospitals.

\section{Results}

Compared with those who self-poisoned, people who cut themselves were more likely to have self-harmed previously and to have received support from mental health services, but they were far less likely to be admitted to the general hospital or receive a psychosocial assessment. Although only $17 \%$ of people repeated self-harm during the 18 months of study, survival analysis that takes account of all episodes revealed a repetition rate of $33 \%$ in the year following an episode: $47 \%$ after episodes of self-cutting and $31 \%$ after self-poisoning $(P<0.001)$. Of those who repeated, a third switched method of self-harm.

\section{Conclusions}

Hospital services offer less to people who have cut themselves, although they are far more likely to repeat, than to those who have self-poisoned. Attendance at hospital should result in psychosocial assessment of needs regardless of method of self-harm.

\section{Declaration of interest}

None. Funding detailed in Acknowledgements.
Self-harm involves a variety of methods commonly categorised as either self-poisoning or self-injury. Acts of self-harm are very common, yet all over the world they present emergency departments and other hospital services with needs for care that these services often fail to meet. ${ }^{1-3}$ In the UK there is a high annual rate of people attending hospital per 100000 population: between 285 and 460 for males, and between 342 and 587 for females. ${ }^{4}$ The clear association with subsequent suicide makes self-harm a strategy target for suicide prevention, ${ }^{5,6}$ and there is a requirement for all hospital services in England and Wales to undertake comprehensive assessments of the psychosocial needs and risks of people who attend because of self-harm. ${ }^{7}$ Epidemiological research has focused mainly on self-poisoning so we know relatively little about self-injury, although it is more widespread than is commonly thought. For example, community studies of adolescents and young adults have found a high incidence of self-cutting and other injuries. ${ }^{8,9}$

Self-injury is important because of its association with high levels of previous self-harm, contact with psychiatric services, subsequent psychiatric admission and suicidal intent. ${ }^{10,11}$ Selfcutting, the most common form of self-injury, is often presumed to reflect low levels of suicidal intent, yet self-cutting, ${ }^{12}$ and cutting combined with poisoning, ${ }^{13}$ have been shown to be risk factors for subsequent suicide. Unfortunately, the self-injury literature is limited by small and unrepresentative samples: study populations are often restricted to one kind of injury such as cutting and confined to patients admitted to hospital or referred to specialist mental health services, excluding the many who leave the emergency departments without undergoing psychosocial assessment. Our research, by contrast, includes all methods of self-harm and is based on a large sample of consecutive emergency department attendances made over 18 months in three English cities. These data form part of the Multicentre Monitoring of Self-Harm project, part of the National Suicide Prevention Strategy for England. ${ }^{6}$

The purpose of this study was to use our uniquely large sample to compare rates of repetition after self-injury with rates after self-poisoning, also determining differences in arrangements for psychosocial assessment and aftercare according to method used. Unlike the conventional analysis of these data, where only the time to the first repeat is incorporated, we undertook an analysis in which all repeat episodes of self-harm were included, thereby representing more closely the emergency department clinician's view of self-harm attendances.

\section{Method}

\section{Study design}

In the three English cities of Oxford, Manchester and Leeds we undertook a multicentre cohort study, collecting data on consecutive patients aged 12 years and older who attended any of the emergency departments in these cities as a result of non-fatal self-harm in the 18 months between March 2000 and August 2001. Researchers collected data soon after the patients had attended each hospital. Our monitoring of self-harm is sanctioned by the local research ethics committees in all three cities. Each of the three centres also has approval to collect data as a result of support under Section 60 of the Health and Social Care Act 2001, although such support was not a requirement at the time of this study. Only pseudonymised data were shared between the three monitoring centres. 


\section{Setting}

The three cities have six emergency departments: one in Oxford, two in Leeds and three in Manchester. These cities represent a spectrum of urban England with Manchester the most and Oxford the least socially deprived of the three. As well as considerable variations in socio-economic characteristics of the cities, there were substantial differences in the mental health services available to assess people following self-harm: a detailed description of catchment areas and self-harm services is available elsewhere, where we also describe how the data for the three centres were combined. ${ }^{4}$

\section{Study population}

Non-fatal self-harm was defined as intentional self-poisoning or self-injury, irrespective of motivation. ${ }^{14}$ Self-poisoning includes the intentional ingestion of more than the prescribed amount of any drug, whether or not there is evidence that the act was intended to result in death. Also included were acts of poisoning with non-ingestible substances, overdoses of 'recreational' drugs, and severe alcohol intoxication where clinical staff thought that the self-harm was intentional. Self-injury was defined as any injury that was intentionally self-inflicted. This included selflaceration, attempted hanging, jumping from a height, burning, swallowing foreign bodies, gas inhalation and traffic-related injuries.

\section{Data collection and analysis}

To identify episodes of self-harm and collect the data, research staff scrutinised assessment forms completed by general hospital and psychiatric staff, emergency department records, psychiatric referrals, medical records and other sources. The emergency department computer systems were searched using deliberately over-inclusive terms, such as 'psychiatric', 'behaving strangely', 'lacerations' or 'appears drunk', and the corresponding paper records were then examined. This method of searching resulted in scrutiny of many cases where the presenting problem did not indicate self-harm as well as cases where there was no referral for a psychosocial assessment. Identifying self-harm episodes using this system has been proven to be reliable ${ }^{15}$ and its use in our study is described in more detail elsewhere. ${ }^{4}$

Data collection was affected by local characteristics and varied during the study period. Researchers in Manchester were unable to obtain some information on admissions and on cases where psychiatric or emergency department staff did not complete an assessment form. In Leeds, people staying overnight on the observation wards associated with emergency departments were included but counted as non-admitted patients, and data from in-patient records were unavailable, precluding identification of some psychosocial assessments and aftercare. Wherever data were unavailable it has been made clear in the analysis, unless the numbers missing were too few to be important.

Data on various demographic and clinical variables were compared according to which of four methods of self-harm was used: self-poisoning, self-cutting, self-injury other than by cutting, and methods involving combinations of self-poisoning and selfinjury. Differences between groups were explored using chisquared tests (when there were more than two groups), odds ratios with $95 \%$ confidence intervals, and the Mantel-Haenzel method for the stratified analysis of odds ratios where confounding was suspected. The patients were subject to variable lengths of follow-up, from 1 day to 18 months, so, taking account of the variable time at risk of repeating, we plotted Kaplan-Meier survival curves with log rank tests to identify differences related to methods of self-harm. The study data were collected in parallel from three cities, producing three different-sized samples: 2401 attendances from Oxford, 3262 from Manchester and 4835 from Leeds. To account for this we examined the effect of weighting and adjustment for clustering in the survival analyses, using Cox's test for the comparison of survival in multiple samples. For the analysis we used SPSS version 14.0 for Windows and Intercooled Stata version 8.0 for Windows.

\section{Results}

\section{Characteristics of study participants}

During the 18 months of study, 7344 people made 10498 visits to the six emergency departments because of self-harm (Table 1). Self-poisoning was the most common form of harm but nearly $20 \%$ of attendances involved self-injury. Most of the combined methods (390/445, 88\%) involved poisoning and cutting. We found a similar pattern of method of harm across the three cities.

Females accounted for $56 \%$ of all attendances and were a little more likely than males to use self-poisoning but, contrary to popular belief, self-cutting occurred in a slightly greater proportion of males (Table 1). Self-injury other than by cutting was far more widespread among males, and the proportion of people who used more than one method on the same occasion was similar for males and females. Those using cutting, or more than one method, were a little younger than those who self-poisoned. Self-injury other than by cutting had an important association with age: of the people who injured themselves, only 16\% (281/1787) of those aged under 45 years used a method other than cutting but this proportion was $24 \%(36 / 149)$ for the age-band 45-54, and as high as $42 \%(22 / 52)$ for those aged 55 and over $\left(\chi^{2}\right.$ for trend=29.56; d.f. $=1 ; P<0.001)$. When compared with self-poisoning, self-injury - especially self-cutting - was closely associated with previous self-harm and with previous contact with mental health services (Table 1).

Attendances at the emergency department were often outside normal working hours, with half (4722/9506) between 20.00 and $03.00 \mathrm{~h}$; time data were missing in $992(9.4 \%)$ cases. The timepattern of attendance was remarkably similar regardless of selfharm method.

\section{General hospital admission and psychosocial assessment}

Admission from the emergency department to the general hospital, mainly to medical or short-stay wards, depended on the method of self-harm used. Overall, $53 \%$ of attendances resulted in general hospital admission (Table 1), but this proportion was far lower for people who had cut themselves (12\%) or used an injury method other than cutting (34\%). There is also a striking association between the method used and whether the person received a psychosocial assessment; in general, around two-thirds of patients were assessed but the proportion was only $42 \%$ among people who attended after self-cutting. Exploring this further, we compared receipt of psychosocial assessment among the self-cutting only group with receipt of assessment after all other methods of self-harm (OR=0.35; 95\% CI 0.30-0.40). Psychosocial assessment is more likely after admission to the general hospital than it is after discharge directly from the emergency department, so we adjusted the above odds ratio by stratified analysis for the confounding effect of hospital admission (Table 2), confirming that there is a clear relationship between self-cutting and a failure to receive psychosocial assessment that is not explained by admission to the general hospital (adjusted $\mathrm{OR}=0.64$; 95\% CI $0.54-0.75$ ). 


\begin{tabular}{|c|c|c|c|c|c|c|}
\hline \multirow[b]{2}{*}{ Variable } & \multicolumn{5}{|c|}{ Method of self-harm } & \multirow[b]{2}{*}{$\chi^{2}$ (3 d.f.) } \\
\hline & All methods & $\begin{array}{l}\text { Self-poisoning } \\
\text { only }\end{array}$ & $\begin{array}{l}\text { Self-cutting } \\
\text { only }\end{array}$ & $\begin{array}{l}\text { Combined } \\
\text { methods }\end{array}$ & $\begin{array}{l}\text { Self-injury other } \\
\text { than by cutting }\end{array}$ & \\
\hline All episodes, $n$ (\% of total) & $10498(100)$ & $8483(80.9)$ & $1283(12.2)$ & $445(4.2)$ & $287(2.7)$ & \\
\hline \multicolumn{7}{|l|}{ Gender and age } \\
\hline Male, $n$ (\%) & 4669 (100) & $3662(78.4)$ & $626(13.4)$ & $209(4.5)$ & $172(3.7)$ & $44.42, P<0.001$ \\
\hline Female, $n(\%)$ & $5829(100)$ & $4821(82.7)$ & 657 (11.3) & $236(4.0)$ & $115(2.0)$ & \\
\hline $\begin{array}{l}\text { Median age, years } \\
\text { (interquartile range) }\end{array}$ & $30(22-40)$ & $31(22-41)$ & $28(21-36)$ & $28(21-37)$ & $29(22-40)$ & $79.09, P<0.001$ \\
\hline Proportion aged $\leqslant 30$ years, $\%$ & 50 & 48 & 59 & 60 & 53 & $66.92, P<0.001$ \\
\hline \multicolumn{7}{|l|}{ Previous history } \\
\hline Previous self-harm, ${ }^{a} n(\%)$ & $6272 / 8643(72.6)$ & $4841 / 7006(69.1 \%)$ & 930/1039 (89.5\%) & $328 / 388(84.5 \%)$ & $173 / 210$ (82.4\%) & $230.25, P<0.001$ \\
\hline $\begin{array}{l}\text { History of mental health } \\
\text { problems, }{ }^{\text {b }} n(\%)\end{array}$ & $5167 / 7802(66.2)$ & 4008/6307 (63.5\%) & 757/954 (79.4\%) & $257 / 340(75.6 \%)$ & 145/201 (72.1\%) & 110.15, $P<0.001$ \\
\hline $\begin{array}{l}\text { Current contact with mental } \\
\text { health services, }{ }^{C} n(\%)\end{array}$ & $1563 / 3720(42.0)$ & $1237 / 3052(40.5 \%)$ & 199/413 (48.2\%) & $82 / 162(50.6 \%)$ & 45/93 (48.4\%) & $15.68, P<0.001$ \\
\hline \multicolumn{7}{|l|}{ Assessment and immediate care ${ }^{d}$} \\
\hline $\begin{array}{l}\text { Admitted to general hospital, } \\
n(\%)\end{array}$ & $3821 / 7236(52.8)$ & $3438 / 5771(59.6)$ & 109/886 (12.3) & 197/353 (55.8) & 77/226 (34.1) & 722.41, $P<0.001$ \\
\hline $\begin{array}{l}\text { Received psychosocial } \\
\text { assessment, }{ }^{\mathrm{e}} n(\%)\end{array}$ & $3822 / 5969(64.0)$ & $3134 / 4641(67.5)$ & $350 / 832(42.1)$ & 210/309 (68.0) & 128/187 (68.4) & 202.57, $P<0.001$ \\
\hline $\begin{array}{l}\text { a. Missing data }=1855(17.7 \%) . \\
\text { b. Missing data }=2696(25.7 \%) \text {. } \\
\text { c. Missing data }=2032(35.3 \%) \text {. Data only } 1 \text { (and } \\
\text { d. Oxford and Leeds data only. } \\
\text { e. Missing data }=1267(17.5 \%) \text { because }\end{array}$ & November 2000 to & March 2001. & & & & \\
\hline
\end{tabular}

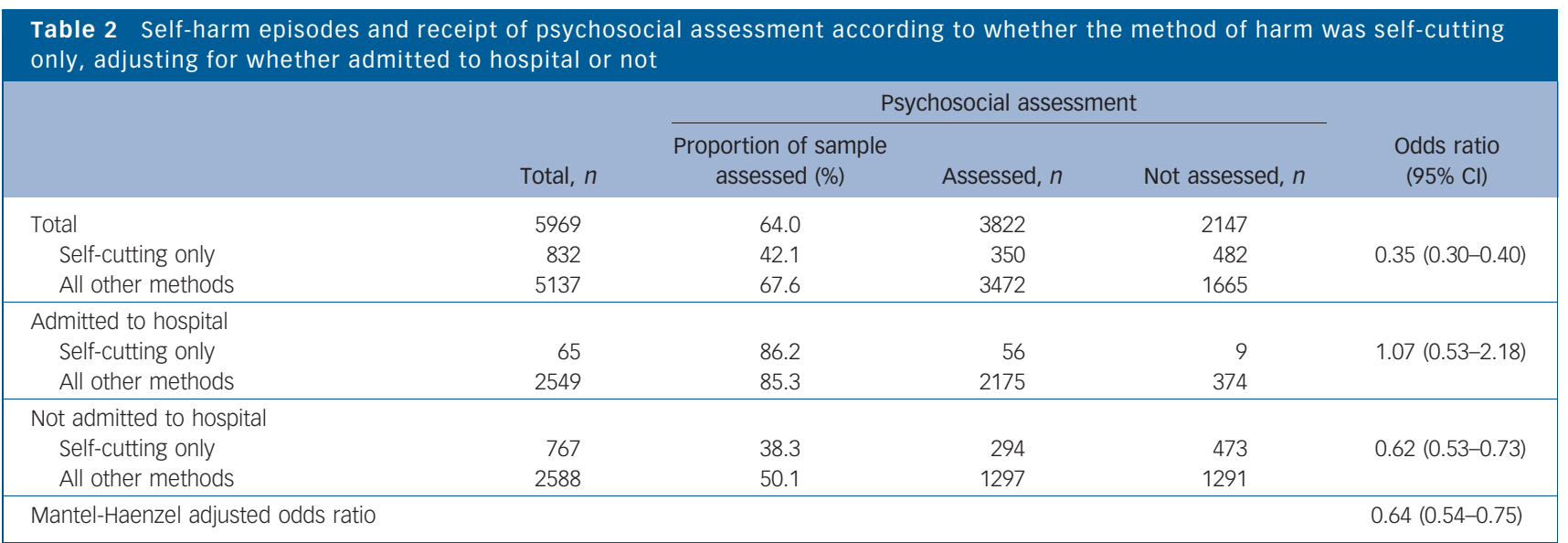

Method of self-harm also affected arrangements for aftercare (Table 3). Being admitted to a psychiatric ward (or returning to one, if already resident on such a unit) occurred occasionally after self-poisoning (9\%) but commonly (34\%) following an injury other than by cutting. Referrals or return appointments to out-patient mental health services were made for around 40\% of patients who poisoned themselves, cut themselves, or used a combination of methods, but were made less often for those who injured themselves other than by cutting - probably explained by their high rate of admission to psychiatric in-patient care. Around a third of episodes, regardless of method of harm used, resulted not in admission to a psychiatric ward or referral to mental health services but in the patient being directed towards receiving care from their general practitioner or to other agencies such as social services, voluntary services, housing support or probation; in some of these cases the patient was referred, whereas in others they were advised to make their own arrangements. Selfdischarging before treatment was completed was most likely to occur following cutting (15\%) and least likely following injuries other than by cutting (7\%) (Table 3$)$.

\section{Repetition of self-harm}

We determined whether the 7344 people who attended hospital following self-harm had returned with another episode during the 18-month study period. Overall, 1234 (17\%) repeated and we found large differences in repetition rate according to the method of self-harm used on the first episode during the study: the least likely method of harm to be followed by a repeat was self-injury other than by cutting (12\%), followed by self-poisoning $(16 \%)$, self-cutting $(25 \%)$ and combined methods $(27 \%)$ $\left(\chi^{2}=67.20\right.$, d.f. $\left.=3, P<0.001\right)$.

When the time from the first episode of self-harm to the first repeat episode was examined using survival statistics, taking account of variable length of follow-up, we found a 19\% repetition rate at 1 year and $23 \%$ at 18 months. There was a striking difference in the pattern of repetition according to method of harm (Fig. 1). Those who cut themselves or used combined methods showed a greater propensity to repeat and did so sooner than those who attended because of poisoning or an injury other than cutting ( $\log$ rank $\chi^{2}=75.37$; d.f. $\left.=3 ; P<0.001\right)$. We also constructed 


\begin{tabular}{|c|c|c|c|c|c|}
\hline \multirow[b]{2}{*}{ Method of self-harm } & \multirow[b]{2}{*}{ Episodes, $n$} & \multicolumn{3}{|c|}{ Aftercare arranged (existing or new referral, $n$ (\%) } & \multirow[b]{2}{*}{ Self-discharged } \\
\hline & & Psychiatric admission & Out-patient referral & GP/other referral & \\
\hline Self-poisoning only & 5768 & $508(8.8)$ & $2459(42.6)$ & $2196(38.1)$ & $605(10.5)$ \\
\hline Self-cutting only & 902 & $132(14.6)$ & $354(39.3)$ & $279(30.9)$ & $137(15.2)$ \\
\hline Combined methods & 337 & $49(14.5)$ & $141(41.8)$ & $107(31.8)$ & 40 (11.9) \\
\hline Self-injury other than by cutting & 202 & $68(33.7)$ & $48(23.8)$ & $71(35.1)$ & $15(7.4)$ \\
\hline All methods ${ }^{a}$ & 7209 & $757(10.5)$ & $3002(41.6)$ & $2653(36.8)$ & $797(11.1)$ \\
\hline Statistical test: $\chi^{2}$ (3 d.f.) & & 155.17, $P<0.001$ & $31.03, P<0.001$ & $21.30, P<0.001$ & $20.49, P<0.001$ \\
\hline
\end{tabular}

and examined these curves for various subgroups by comparing the pattern for males and females, for each of the three cities in the study, and for three age-bands (curves not shown): the pattern in each case was closely similar to the unstratified curves shown in Fig. 1.

The curves in Fig. 1 are based on each separate person appearing just once and accounted for until either the first repetition of self-harm or the end of the study, whichever was sooner. Because, in practice, people repeat self-harm more than once, we constructed another Kaplan-Meier survival curve (Fig. 2) in which the recurrent events were all accounted for: each person remained at risk after the first repetition until the next episode, and at risk after that one, and so on until the end of the study, ${ }^{16,17}$ using the gap time unrestricted formulation for this analysis. ${ }^{18}$ In this way, every episode in the 18-month period (apart from 28 of the 10498 episodes, because data on timing were absent) was included in the analysis. Each repeat episode and its associated method of harm thereby becomes an index episode.

These curves show a similar pattern to that seen in the more conventional analysis of Fig. 1. Episodes of cutting, or where combined methods were used, indicated a greater propensity for repetition, and sooner, than did episodes of poisoning or those involving an injury other than by cutting ( $\log$ rank $\chi^{2}=136.52$; d.f. $=3 ; P<0.001$ ). Survival times according to method of self-harm and adjusted by sample weight and clustering by hospital (using robust standard errors) showed significant differences that were similar to the unadjusted values. These recurrent-event curves more closely represent the emergency department clinician's view of each new self-harm attendance at hospital, pointing to much worse outcomes for all groups than appear to be the case using the more conventional analysis. We found a 33\% likelihood of further self-harm in the year following an episode of self-harm. This figure varied according to the method of the episode in question: from a $31 \%$ likelihood of repetition after an episode of selfpoisoning to $47 \%$ after self-cutting. Focusing on a shorter followup period, $16 \%$ of episodes were followed by a repeat within 30 days; by this early stage those who attended because of cutting or a combination of methods were already far more likely to repeat (23\% and $22 \%$ respectively) than those who had poisoned $(15 \%)$ or injured themselves by a method other than cutting (14\%) $\left(\log \operatorname{rank} \chi^{2}=58.66\right.$, d.f. $\left.=3, P<0.001\right)$. These values are all taken from the life-tables that were constructed to make up the curves in Fig. 2, but they can be estimated directly from inspection of the curves.

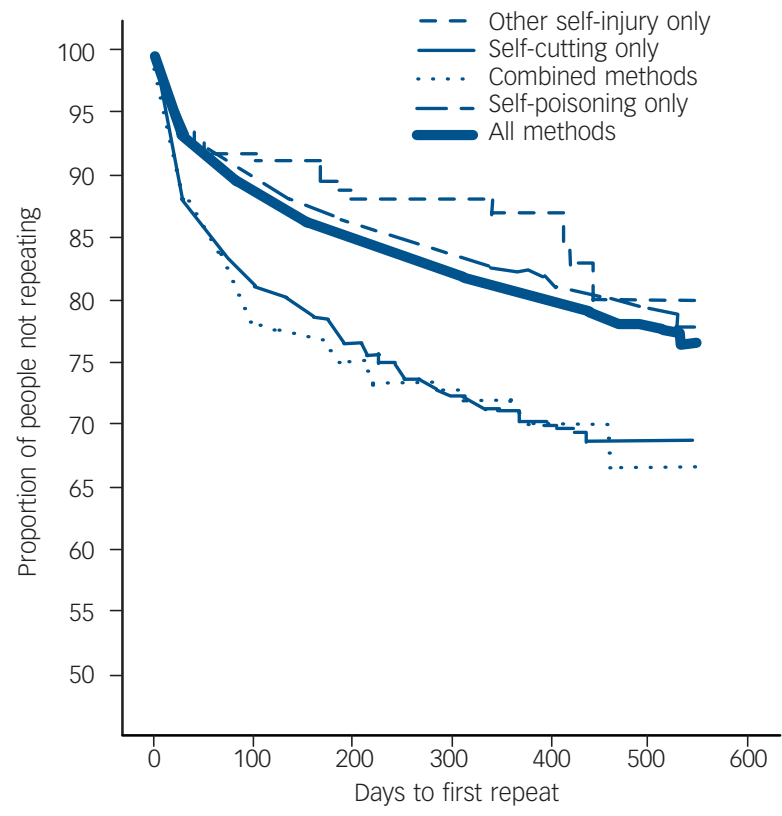

Fig. 1 Repetition of self-harm according to method of harm: Kaplan-Meier curves represent time from the first episode during study period to the first repeat episode.

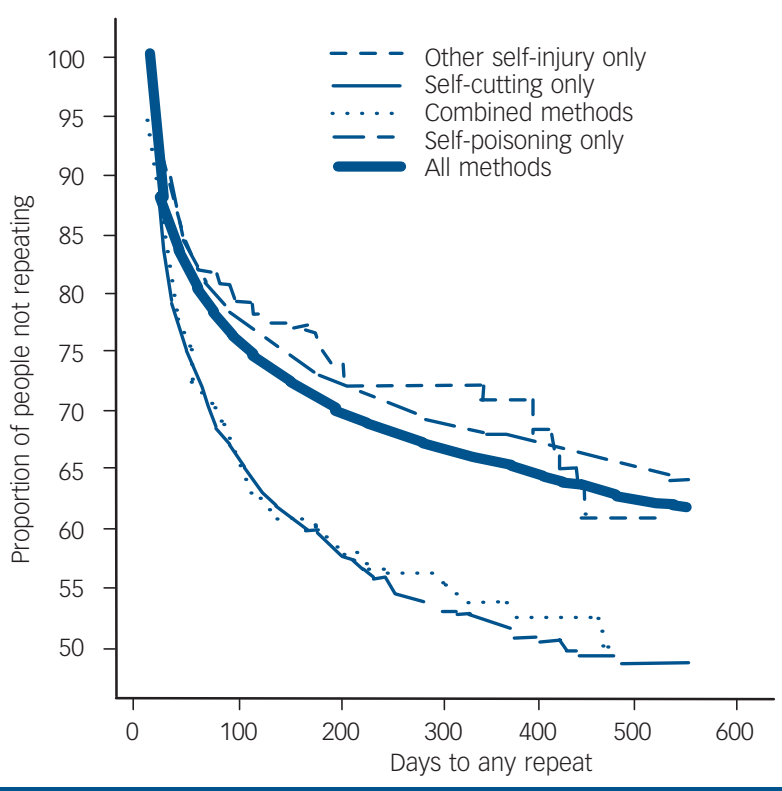

Fig. 2 Repetition of self-harm according to method of harm: Kaplan-Meier curves calculated using recurrent event analysis (each repeat episode treated as an index episode). Curves represent time from each episode to a repeat. 
Of the 1234 people who self-harmed more than once during the study period, $404(33 \%$; $95 \%$ CI $30-35)$ used a different method (another of the other three categories) of self-harm in a later episode. Where the method used in the first episode was self-poisoning, $21 \%$ of those who repeated (203/949) altered method during the study period; where the first episode was by self-cutting, $61 \%(116 / 189)$ later switched to a different method of harm, nearly always to self-poisoning or a combination of poisoning and an injury. Alteration of method was the usual consequence after injuries other than by cutting $(21 / 24,88 \%)$ or a combination of methods $(64 / 72,89 \%)\left(\chi^{2}=261.65\right.$; d.f. $=3$; $P<0.001)$.

\section{Discussion}

Our data and methods of analysis lead us to three main findings that are considered in detail below: repetition of self-harm is far more likely than previously accepted; switching of method is commonplace; and self-cutting is more indicative of risk than is usually thought.

\section{Limitations}

These data form a large and recent sample that can be considered as reasonably representative of self-harm care in urban settings in the UK, identified using a definition of self-harm that was common to all three clinical centres. The study had three potential areas of weakness. First, there were missing data arising from inevitable variations in data collection from the dissimilar clinical services for self-harm across the three cities. As with similar monitoring systems of clinical care, data for a substantial proportion of the patients were extracted from routine clinical case records so were sometimes missing; valid sample sizes therefore vary according to which variables are being studied and we have reported the results to display these variations. A few analyses could only be undertaken with data for two of the three centres.

Second, repetition could not take account of people who repeated but attended a hospital outside of the city in question; repetition rates may thereby be slight underestimates but missing data are unlikely to have compromised the comparisons based on method of harm. Third, our findings do not generalise to episodes of self-harm that do not lead to hospital attendance.

\section{Main findings}

Around four out of five hospital attendances after self-harm in this multicentre study were due to self-poisoning. Cutting was the predominant method of self-injury, but many people injured themselves in other ways or used a combination of methods. This pattern of poisoning and injury is similar to that seen around Europe, according to multicentre investigations. ${ }^{19,20}$ Half of all patients were aged over 30 years but cutting was particularly associated with people aged 30 or less, as were methods involving combinations of poisoning and injury, which is in line with findings from community-based studies of self-harm in young people. $^{8}$ People who self-poisoned or injured themselves by methods other than cutting (methods that tend to be more severe in nature) were older. Severity of method among older people who self-harm may partly explain why they are especially likely to be admitted from the emergency department into the general hospital. $^{21,22}$

We were not surprised to find more males than females among those who self-injured by means other than cutting because of the more violent methods sometimes involved. However, we also recorded nearly as many episodes of self-cutting in males as in females. This finding contradicts the belief held by many that cutting is largely a female behaviour and confirms the findings of recent published work..$^{10,23,24}$ Self-cutting sometimes raises less concern than do other methods of self-harm, being presumed to reflect less distress and lower suicidal intent. Our findings are to the contrary: people who cut themselves were the most likely to have self-harmed previously, to have used mental health services in the past, and are among those most likely to be currently receiving support for a mental health problem, all of which are known risk factors for fatal and non-fatal repetition of self-harm. ${ }^{12,13,25}$

The overall repetition rate based on the recurrent event analysis (Fig. 2) was, at $31 \%$, about twice the estimate (16\%) suggested by a systematic review of 1-year rates of non-fatal repetition following self-harm. ${ }^{26}$ Our current findings demonstrate how an alteration in the method of analysis has a major effect on the interpretation of the data: when estimating the prognosis for someone who has attended the emergency department because of self-harm, on average that person has around a one in three likelihood of harming themselves again within the next year. Analyses based only on simple proportions, or on survival analysis only to the first repeat, result in serious underestimates of these relentlessly high rates of repetition.

We found a striking association between methods of self-harm and non-fatal repetition. After cutting or a combination of injury and poisoning, a patient was very likely to self-harm again and to do so soon. Inclusion of all episodes of self-harm in the survival analysis (Fig. 2) showed that someone who has attended the emergency department because of self-poisoning has around a one in three likelihood of harming themselves again within the next year; if the patient has cut himself or herself (in combination with poisoning or not) then that likelihood is about one in two. Much of this repetition happens very soon: by 30 days 16\% of self-harm episodes have been followed by another one, and if the index episode features cutting this proportion is almost one in four.

It is, however, simplistic to interpret the pattern of repetition simply as showing that people who self-poison are less likely to repeat than are people who cut themselves because so many people switch method. Our study had an average follow-up of 9 months; a third of those who repeated switched method at least once in this short time. On the other hand, we did show that when the first episode in our study was by self-cutting a switch was three times as likely as it was if the first episode was by self-poisoning $(61 \%$ v. $21 \%)$. It has been shown that a majority of people who die by suicide after self-harm use a different method in their final act; ${ }^{11}$ perhaps those who switch methods between episodes of non-fatal self-harm have greater risk of subsequent suicide.

We observed a disappointing delivery of psychosocial assessment after self-harm. Despite their many past episodes, their previous mental healthcare and a high likelihood of repetition, patients who cut themselves received a psychosocial assessment on a minority of hospital attendances. Improving assessment arrangements in emergency departments would especially benefit people who cut themselves because they are the most likely to leave for home from the emergency department rather than be admitted and subsequently assessed; when they are assessed, people who attended because of self-injury are often deemed to need mental healthcare, with in-patient psychiatric care especially likely.

\section{Implications of the study}

We have demonstrated that the likelihood of repetition after any method of self-harm is high; much higher than is generally believed, especially after episodes involving self-cutting. Our work 
also points to a discrepancy between what the service offers and what patients might need after self-harm. We have confirmed other findings from England that episodes where people had cut themselves were characterised by the highest levels of some of the known risk factors for poor outcome, yet these people received the lowest provision of psychosocial assessment. ${ }^{27}$ This discrepancy between need and provision exists despite growing evidence for the possible benefits of a psychotherapeutic intervention specifically designed for women with repeatedly self-injurious and suicidal behaviour. ${ }^{28,29}$

On account of the high prevalence of switching methods between episodes, which undermines any attempt to determine risk according to the method of harm used, our conclusion is that everyone who attends hospital because of self-harm will need to be taken seriously regardless of the method or the medical severity of the self-harm. Everyone should be offered competent psychosocial assessment of his or her needs. Any aftercare that is arranged will need to take place soon after the episode in question; perhaps it should provide for community-based assessment of patients who return home before they can be assessed.

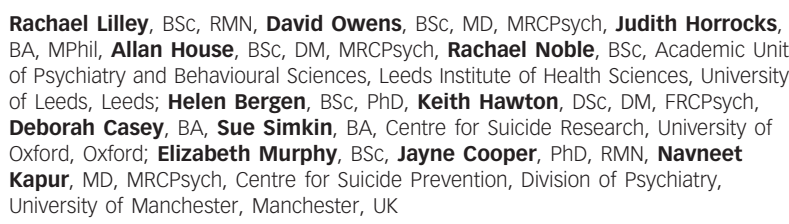

Correspondence: Dr David Owens, Academic Unit of Psychiatry and Behavioural Sciences, Leeds Institute of Health Sciences, University of Leeds, Charles Thackrah Building, 101 Clarendon Road, Woodhouse, Leeds LS2 9LJ. Email: d.w.owens@leeds.ac.uk

\section{Acknowledgements}

The research centre in Oxford was funded by the Department of Health in England Researchers in Leeds were funded by the mental health charity Leeds MIND and the Leeds Mental Health NHS Trust. In Manchester the project was funded by Manchester Health Authority, South Manchester University Hospitals NHS Trust, Manchester Healthcare NHS Trust, North Manchester Healthcare NHS Trust and the Mental Health Services of Salford NHS Trust. The authors from Oxford thank Elizabeth Bale, Anna Shepherd and members of the general hospital psychiatric services for their assistance with data collection. The Healey and Stella Dickson. The authors from Leeds thank colleagues in the emergency departments clinicians and, in particular, the clerical and administrative staff. The views expressed are solely those of the authors.

\section{References}

1 Owens D, House A. General hospital services for deliberate self-harm. J Roy Coll Phys London 1994; 28: 370-1.

2 Doshi A, Boudreaux ED, Wang N, Pelletier AJ, Camargo CA. National study of US Emergency Department visits for attempted suicide and self-inflicted injury, 1997-2001. Ann Emerg Med 2005; 46: 369-75.

3 Claasen CA, Trivedi MH, Shimizu I, Stewart S, Larkin GL, Litovitz T. Epidemiology of nonfatal deliberate self-harm in the United States as described in three medical databases. Suicide Life Threat Behav 2006; 36 : 192-212.

4 Hawton K, Bergen H, Casey D, Simkin S, Palmer B, Cooper J, Kapur N, Horrocks J, House A, Lilley R, Noble R, Owens D. Self-harm in England: a tale of three cities. Soc Psychiatry Psychiatr Epidemiol 2007; 42: 513-21.

5 Vastag B. Suicide prevention plan calls for physicians' help. JAMA 2001; 285 2701-3

6 Department of Health. Suicide Prevention Strategy for England. TSO (The Stationery Office), 2002.
7 National Institute for Health and Clinical Excellence. Self-harm: The Shortterm Physical and Psychological Management and Secondary Prevention of Self-harm in Primary and Secondary Care. NICE, 2004.

8 Hawton K, Rodham K, Evans E, Weatherall R. Deliberate self-harm in adolescents: self-report survey in schools in England. BMJ 2002; 325: 1207-11

9 Whitlock J, Eckenrode J, Silverman D. Self-injurious behaviours in a college population. Pediatrics 2006; 117: 1939-48.

10 Horrocks J, Price S, House A, Owens D. Self-injury attendances in the accident and emergency department. Clinical database study. Br J Psychiatry 2003; 183: 34-9.

11 Harriss L, Hawton K, Zahl D. Value of measuring suicidal intent in the assessment of people attending hospital following self-poisoning or selfinjury. Br J Psychiatry 2005; 186: 60-6.

12 Cooper J, Kapur N, Webb R, Lawlor M, Guthrie E, Mackway-Jones K, Appleby L. Suicide after deliberate self-harm: a 4 year cohort study. Am J Psychiatry 2005; 162: 297-303.

13 Owens D, Wood C, Greenwood DC, Hughes T, Dennis M. Mortality and suicide after non-fatal self-poisoning: 16-year outcome study. $\mathrm{Br} J$ Psychiatry 2005; 187: 470-5.

14 Hawton K, Zahl D, Weatherall R. Suicide following deliberate self-harm: longterm follow-up of patients who presented to a general hospital. $\mathrm{Br} J$ Psychiatry 2003; 182: 537-42.

15 Sellar C, Goldacre MJ, Hawton K. Reliability of routine hospital data on poisoning as measures of deliberate self-poisoning in adolescents $J$ Epidemiol Community Health 1990; 44: 313-5.

16 Machin D, Cheung YB, Parmar M. Survival Analysis: A Practical Approach. John Wiley \& Sons, 2006

17 Baethge C, Schlattmann P. A survival analysis for recurrent events in psychiatric research. Bipolar Disord 2004; 6: 115-21.

18 Kelly P, Lim L. Survival analysis for recurrent event data: an application to childhood infectious diseases. Stat Med 2000; 19: 13-33.

19 Schmidtke A, Bille-Brahe $U$, De Leo D, Kerkhof A, Bjerke T, Crepet $P$, Haring $C$, Hawton $K$, Lonnqvist J, Michel K, Pommereau X, Querejeta I Phillipe I, Salander-Renberg E, Temesvary B, Wasserman D, Fricke S, Weinacker B, Sampaio-Faria JG. Attempted suicide in Europe: rates, trends and sociodemographic characteristics of suicide attempters during the period 1989-1992. Results of the WHO/EURO Multicentre Study on Parasuicide. Acta Psychiatr Scand 1996; 93: 327-38.

20 Michel K, Ballinari $P$, Bille-Brahe U, Bjerke T, Crepet P, De Leo D, Haring C, Hawton K, Kerkhof A, Lonnqvist J, Querejeta I, Salander-Renberg E, Schmidtke A, Temesvary B, Wasserman D. Methods used for parasuicide: results of the WHO/EURO Multicentre Study on Parasuicide. SOC Psychiatry Psychiatr Epidemiol 2000; 35: 156-63.

21 Szanto K, Gildengers A, Mulsant BH, Brown G, Alexopoulos GS, Reynolds CF. Identification of suicidal ideation and prevention of suicidal behaviour in the elderly. Drugs Aging 2002; 19: 11-24.

22 Marriott R, Horrocks J, House A, Owens D. Assessment and management of self-harm in older adults attending accident and emergency: a comparative cross-sectional study. Int J Geriatr Psychiatry 2003; 18: 645-52.

23 Hawton K, Harriss L, Simkin S, Bale E, Bond A. Self-cutting: patient characteristics compared with self-poisoners. Suicide Life Threat Behav 2004; 34: 199-208.

24 Fortune S. An examination of cutting and other methods of DSH among children and adolescents presenting to an outpatient psychiatric clinic in New Zealand. Clin Child Psychol Psychiatry 2006; 11: 407-16.

25 Kapur N, Cooper J, King-Hele S, Webb R, Lawlor M, Rodway C, Appleby L. The repetition of suicidal behaviour. J Clin Psychiatry 2006; 67: 1599-609.

26 Owens D, Horrocks J, House A. Fatal and non-fatal repetition of self-harm. Systematic review. Br J Psychiatry 2002; 181: 193-9.

27 Gunnell D, Bennewith O, Peters TJ, House A, Hawton K. The epidemiology and management of self-harm amongst adults in England. $J$ Public Health 2004; 27: 67-73.

28 Linehan MM, Armstrong HE, Suarez A, Allmon D, Heard H. Cognitivebehavioral treatment of chronically parasuicidal borderline patients. Arch Gen Psychiatry 1991; 48: 1060-4.

29 Linehan MM, Comtois KA, Murray MA, Brown MZ, Gallop RJ, Heard HL, Korslund KE, Tutek DA, Reynolds SK, Lindenboim N. Two-year randomized controlled trial and follow-up of dialectical behavior therapy vs therapy by experts for suicidal behaviors and borderline personality disorder. Arch Gen Psychiatry 2006; 63: 757-66. 